\title{
Joint predictability of physical activity and body weight status on health-related quality of life of patients with hypertension
}

\author{
Taofeek O. Awotidebe ${ }^{1, *}$, Victor O. Adeyeye ${ }^{2}$, Suraj A. Ogunyemi ${ }^{23}$, Luqman A. Bisiriyu4, Rufus A. Adedoyin', Michael 0. Balogun ${ }^{2,3}$, \\ Rasaaq A. Adebayo ${ }^{2,3}$, Omolara D. Amosun' \\ 'Department of Medical Rehabilitation, College of Health Sciences, Obafemi Awolowo University, Ile - Ife, Nigeria \\ ${ }^{2}$ Cardiac Care Unit, Medical Out-Patient Department, Ife Hospital Unit, Obafemi Awolowo University Teaching Hospitals Complex, Ile - Ife, Nigeria \\ ${ }^{3}$ Department of Medicine, College of Health Sciences, Obafemi Awolowo University, Ile - Ife, Nigeria \\ ${ }^{4}$ Department of Demography and Social Statistics, Faculty of Social Sciences, Obafemi Awolowo University, lle - Ife, Nigeria
}

This study investigated the predictability of physical activity (PA) and body weight status (BWS) on health-related quality of life (HROLL) of patients with hypertension. A cross-sectional study involved $250 \mathrm{pa}-$ tients with hypertension ( $\geq 140 / 90 \leq 179 / 109 \mathrm{mmHg}$ ) selected from government hospitals in Osun State, Nigeria. Purposive sampling technique was used to select participants. Socio-demographic characteristics and cardiovascular parameters were recorded. PA and HROOL were assessed using the International Physical Activity Questionnaire and Short Form health survey questionnaire respectively. Sufficient PA equals $\geq 150 \mathrm{~min} / \mathrm{wk}$ while BWS was defined using body mass index classification. Data were analyzed using descriptive and inferential statistics. Alpha level was set at $P<0.05$. Of all participants, $63.6 \%$ reported sufficient PA and $78.4 \%$ was either overweight or obese. The HROoL of participants become poorer in all domains with higher body weight. The $\mathrm{HROOL}$ including role limitation due to physical health (RLdPhp) and emotional problems (RLdEmp) had worst scores. Participants in the categories of normal and overweight/obese with sufficient PA demonstrated higher (better) HRQOL in all domains than those with insufficient $\mathrm{PA}(P<0.05)$. When adjusted for body weight, significant differences were found in all domains of HROoL except in RLdPhp, RldEmp, and bodily pain $(P>0.05)$. There were significant correlations between $P A$ and all domains of HROoL except in RldEmp, emotional well-being and bodily pain $(P>0.05)$. Regression models established PA as a significant predictor of $\mathrm{HROOL}$. Sufficient PA is a better predictor of $\mathrm{HROOL}$ among patients with hypertension irrespective of BWS. Regular PA is recommended for improving HRQOL among patients with hypertension.

Keywords: Predictability, Physical activity, Body weight status, Health-related quality of life, Hypertension

\section{INTRODUCTION}

The World Health Organization (WHO) projects that over the next 10 years Africa will experience the largest increase in death rates from cardiovascular disease (CVD) as a result of increasing prevalence of hypertension (World Health Organization [WHO], 2011). Africa, a continent of 53 countries with one billion population is not only threatened by a huge burden of infectious diseases but also bears a considerable proportion of the world's CVD burden due to high prevalence of hypertension (Hajjar et al.,
2006; WHO, 2005a). Unfortunately, the dearth of valid epidemiological data to describe the magnitude of hypertension preponderance is a significant shortcoming in the region. Nonetheless, hypertension has been identified as an important risk factor for $\mathrm{CVD}$ and is portending an unimaginable public health disasters for sub-Sahara Africa unless urgent actions are taken (BeLue et al., 2009; van de Vijver et al., 2013).

Hypertension is associated with stroke, hypertensive heart disease, cardiac arrest, myocardial infarction, congestive heart and kidney failures (Alberts et al., 2005; Bygbjerg, 2012). There are
*Corresponding author: Taofeek O. Awotidebe (iD https://orcid.org/0000-0002-8583-9467 Department of Medical Rehabilitation, College of Health Sciences, Obafemi Awolowo University, Ile - Ife, Nigeria

Tel: +234-8037196021, E-mail: tidebet@yahoo.com

Received: August 11, 2017 / Accepted: October 8, 2017
This is an Open Access article distributed under the terms of the Creative Commons Attribution Non-Commercial License (http://creativecommons.org/licenses/by-nc/4.0/) which permits unrestricted non-commercial use, distribution, and reproduction in any medium, provided the original work is properly cited. 
known myriad of risk factors for hypertension including but not limited to advancing age, rapid urbanization, series of lifestyle changes which include poor dietary habits, heavy alcohol abuse, cigarette smoking, stress, poor socio-economic status, obesity and physical inactivity, thus contributing to high prevalence of hypertension (Chobanian et al., 2003; Kearney et al., 2005). Evidence from epidemiological studies have shown that individuals with low physical activity (PA) coupled with overweight/obesity were almost twice more likely than those with normal weight to be at higher risk of CVD event (Sobngwi et al., 2002; Wang et al., 2006). Indeed, physical inactivity has been identified as the fourth risk factor for death but is rapidly advancing to become the leading risk for global morbidity and mortality (Bull and Bauman, 2011; WHO, 2009).

In the recent time, epidemiological studies have shown that hypertension and obesity are important factors contributing to the impairment of health-related quality of life (HRQoL) (Ogunlana et al., 2009; Pan et al., 2011). Despite the fact that mild to moderate hypertension is generally asymptomatic, its detection, and diagnosis may negatively impact on HRQoL of individuals with hypertension (Maruf et al., 2013). Although evidence from interventional studies have shown that pharmacological treatment of hypertension helps to lower blood pressure and reduce target organ damage (Familoni et al., 2004; Salako et al., 2004), successful treatment rate of hypertension is still below optimal level (Awotidebe et al., 2014; Pescatello et al., 2004). Notably, factors contributing to unsuccessful treatment of hypertension and poor HRQoL include adverse effect of antihypertensive medications and cost, labeling or beliefs and attitudes about illness and treatment (Maruf et al., 2013; Ogunlana et al., 2009). Fortunately, substantial evidence from several studies have shown that participation in regular and sufficient PA is associated with reduction in blood pressure, and reduction in CVD risk (Maruf et al., 2013; Pan et al., 2011; Tsai et al., 2004; Warburton et al., 2006).

There is no doubt that reduction in body weight lowers blood pressure and subsequently improves HRQoL (Pan et al., 2011; Tsai et al., 2004). However, achieving an optimal body weight is an enormous challenge for overweight or obese individuals presenting with or without hypertension. Nevertheless, it is not known whether regular engagement in sufficient PA with an unchanged body weight status translates to satisfying HRQoL among patients with hypertension. Understanding the import of HRQoL as a health outcome could help to capture a person's perception of overall health status and as well help to inform decisions on resource allocation for effective management of hyperten- sion (WHO, 2005b).

In view of this, many health authorities have advocated the adoption of lifestyle modifications including regular and sufficient PA and body weight control programmes as nonpharmacological approaches for effective hypertension control and satisfying HRQoL (Chobanian et al., 2003; WHO, 2003). However, the extent to which both PA and body weight status jointly impact on HRQoL of patients with hypertension remains poorly understood. Furthermore, a few studies have examined the combined effect of PA and body weight status on HRQoL of patients with hypertension in Nigeria. Hence, the purpose of this study was to investigate the joint predictability of PA and body weight status on HRQoL of Nigerian patients with mild to moderate hypertension

\section{MATERIALS AND METHODS}

\section{Participants and locations}

Participants for this study were individuals with mild to moderate hypertension $(\geq 140 / 90 \leq 179 / 109 \mathrm{mmHg}$ ) receiving treatment at selected government hospitals in Osun State, Nigeria. Purposive sampling technique was used to recruit participants from Ife Hospital Unit, Ile - Ife and Wesley Guild Hospital, Ilesha, both belonging to the Obafemi Awolowo University Teaching Hospitals Complex and State Government Hospital, Asubiaro, Osogbo, Osun State, Nigeria. Eligibility for inclusion were patients with clinical diagnosis of mild to moderate hypertension, receiving treatment at the Consultant Out-Patient Department, Cardiac Care Units of the selected government hospitals, self-reported optimal blood pressure control and regular use of prescribed antihypertensive medications. They were excluded from the study if presented with uncontrolled hypertension $(\geq 180 / 110$ $\mathrm{mmHg}$ ), unstable angina or severe medical co-morbidities such as uncontrolled type 2 diabetes, asthma, and previous history of myocardial infarction or neurological conditions including stroke. They were also excluded if presented with difficulty in understanding or inability to complete the questionnaires due to dementia.

The sample size for this study was based on a sample size formula for cross-sectional survey. The sample size was calculated using the computer program for epidemiologists (PEPI), version 3.01, employing the formula for estimating sample size for single proportion as described by Abramson and Gahlinger (2001). The following parameters were considered to arrive at a minimum sample size for this study; a prevalence rate of $36.6 \%$ of hypertension was reported among elderly individuals in Ile - Ife using the 
140/90 mmHg cutoff point (Adedoyin et al., 2008). Furthermore, a precision margin of $5 \%$ with a standard normal deviate of 1.96 at $95 \%$ confidence interval was chosen. Thereafter, a maximal allowable difference from the true proportion of $5 \%(0.5)$ was considered and eventually, a sample size of 198 was estimated. However, the sample size was increased to 250 to allow for $10 \%-20 \%$ incomplete response or missing data with the view to improving the validity of data.

\section{Protocol design}

This cross-sectional study involved patients with mild to moderate hypertension from selected government hospitals in Osun State, Nigeria. Ethical approval for the study was obtained from the Health Research and Ethics Committee of the Institute of Public Health (IPHOAU/12/421), Obafemi Awolowo University, Ile - Ife, Osun State, Nigeria. Permission to recruit prospective participants was sought and obtained from various Heads/Consultant-in-Charge of the Cardiac Care Units of the selected hospitals after explaining the purpose of study. Furthermore, the purpose of the study was explained to the participants and written informed consent was obtained. Socio-demographic characteristics including age, sex, occupation and monthly income were recorded.

\section{Assessment of anthropometric characteristics and cardiovascular parameters}

Anthropometric measures including current body weight and height were measured using standard procedures. Furthermore, body mass index (BMI) (weight $[\mathrm{kg}] /$ height $\left[\mathrm{m}^{2}\right]$ ) was calculated and classified as underweight $\left(<18.5 \mathrm{~kg} / \mathrm{m}^{2}\right)$, normal weight $\left(18.5-24.9 \mathrm{~kg} / \mathrm{m}^{2}\right)$, overweight $\left(25.0-29.9 \mathrm{~kg} / \mathrm{m}^{2}\right)$ and obese (>30 kg/m²) (WHO, 1995). Body weight status (BWS) was defined as BMI that remains the same (unchanged) in the last 3 months. Cardiovascular parameters including systolic blood pressure (SBP), diastolic blood pressure and heart rate (HR) were all measured in sitting position after rested for about $10 \mathrm{~min}$ of arriving the venue of the study. Thereafter, PA level and HRQoL were assessed using the Short-Form International Physical Activity Questionnaire and Short Form-36 (SF-36) Health Survey Questionnaire respectively.

\section{Assessment of PA level}

The Short Form version of the International Physical Activity Questionnaire (IPAQ) was used to assess PA in this study. The questionnaire has an acceptable test-retest reliability and criterion validity in Nigerian population (Oyeyemi et al., 2011). Partici- pants were asked the number of days they did vigorous PA, moderate PA excluding walking, then also walking, as well as the number of hours and minutes per day they did the three kinds of activities in the last 7 days respectively. The PA included any PA they did: (a) at work, (b) as part of house and yard work, (c) to get from place to place, and (d) in spare time for recreation, exercise or sport, but with no information on frequency and duration for these separate domains. Respective total hours for vigorous PA, moderate PA and walking were calculated.

A metabolic equivalent (MET)-hr was derived by multiplying the respective total hours with the MET value of vigorous PA $(\mathrm{MET}=8.0)$, moderate PA $(\mathrm{MET}=4.0)$ and walking $(\mathrm{MET}=3.3)$, and then adding all three (IPAQ 2005). PA levels were initially classified as low, moderate, or high intensity, defined by the IPAQ core group (http://www.ipaq.ki.se) as follows: Low-no activity or some activity reported, but not enough to satisfy the requirements of the other activity categories; Moderate-any of the following 3 criteria: (a) 3 or more days of vigorous-intensity activity for at least 20 min per day, (b) 5 or more days of moderate intensity activity or waking for at least $30 \mathrm{~min}$ per day, or (c) 5 or more days of any combination of walking, moderate intensity, or vigorous-intensity activities achieving a minimum of 600 MET-minutes per week; High — either of the following 2 criteria: (a) 3 or more days of vigorous-intensity activity accumulating at least 1,500 MET-minutes per week or (b) 7 days of any combination of walking or moderate- or vigorous intensity activities achieving a minimum of 3,000 MET-minutes per week. These 3 groups were then recategorized as sufficient or insufficient PA. Sufficient PA group included participants in the moderate- or high intensity categories who met the WHO PA recommendation. According to the new WHO global standard, satisfying the recommendations for healthy PA was defined as engaging in at least $150 \mathrm{~min}$ of moderate-intensity activity per week, 75 min of vigorous-intensity activity per week, or an equivalent combination of moderate- and vigorous-intensity activity (WHO, 2010).

\section{Assessment of HRQoL}

The HRQoL of participants was assessed using the Medical Outcomes Study Short Form-36 (SF-36) Health Survey Questionnaire. The SF-36 item is one of the most widely used generic measures of HRQoL with good psychometric properties and substantial data on its applicability in clinical and research settings in Africa (Ekwunife et al., 2011; Ware and Gandek, 1998). The 36-items health survey tool assesses eight health dimensions referred to as subscales namely physical functioning (10 items), role 
limitations due to physical problems (RLdPhp: 4 items), role limitation due to emotional problems (RLdEmp: 3 items), bodily pain ( 2 items), general health ( 5 items), vitality ( 4 items), social functioning ( 2 items), and emotional well-being ( 5 items). These subscales' scores were summarized into physical and mental composite summaries (physical composite summary [PCS] \& mental composite summary [MCS]) domains. Individual SF-36 items were recoded, summed and transformed. The health concepts described by the SF-36 range in score from 0-100, with higher scores indicating higher levels of function or better health (Ware and Gandek, 1998). The cultural adaptation and psychometric properties of SF-36 in Yoruba language showed that the convergent validity was satisfactory, ranging from 0.421 to 0.907 , discriminant validity was also satisfactory except for item ' 1. ' The intraclass coefficient for the test-retest reliability ranges between 0.636 and 0.843 for scales and 0.783 and 0.851 for domains (Mbada et al., 2015).

\section{Statistical analyses}

Descriptive statistics of frequency, percentage, mean and standard deviation were used to summarize data. Physical characteristics and PA (MET-min/wk) level of participants were compared between genders using $t$-test while chi-square test of association was used for the categorical variables. Participants' HRQoL with sufficient PA and insufficient PA with respect to normal weight, overweight and obese were also evaluated using independent $t$-test. Pearson moment correlation test was used to determine the relationships between HRQoL subscales and each of age, BMI and PA level (MET-min/wk). Multiple linear regression analyses were conducted by block to establish the important predictors of HRQoL among patients with hypertension. All subscales of HRQoL were chosen as outcome variables while age, sex, PA, and BMI were used as predictor variables for the models. The demographic variables were entered in the first block, PA was entered in the second block and BMI was entered in the third block. Alpha level was set at $P<0.05$. The IBM SPSS Statistics ver. 19.0 (IBM Co., Armonk, NY, USA) was used to perform statistical analyses.

\section{RESULTS}

Table 1 shows socio-demographic characteristics and clinical profiles of all participants. There were more female than male participants and about two-thirds, $62.8 \%$ of participants were older than 65 years. More than half, $57.6 \%$ of participants had greater than 5 years onset of diagnosis of hypertension. A majority, $74.4 \%$
Table 1. Socio-demographic and clinical characteristics of all participants

\begin{tabular}{lc}
\hline Variable & No. (\%) \\
\hline Sex & \\
Male & $102(40.8)$ \\
Female & $148(59.2)$ \\
Age (yr) & \\
$41-65$ & $93(37.2)$ \\
$>65$ & $157(62.8)$ \\
Occupation & \\
Artisan/farmer & $70(28.0)$ \\
Business & $47(18.8)$ \\
Civil servant & $44(17.6)$ \\
Retiree & $89(35.6)$ \\
Marital status & \\
Single/divorced & $11(4.4)$ \\
Married & $177(70.8)$ \\
Widow/widower & $62(24.8)$ \\
Educational level & \\
Non formal/primary & $112(44.8)$ \\
Secondary & $88(35.2)$ \\
Postsecondary & $50(20.0)$ \\
Monthly income & $128(51.2)$ \\
$<$ N100,000 & $123(49.2)$ \\
N100,000-N200,000 & $74(29.6)$ \\
Onset of diagnosis (yr) & $53(21.2)$ \\
$<5$ & \\
$\geq 5$ & $106(42.4)$ \\
Medication prescribeda) & $144(57.6)$ \\
ACE-l & \\
ARB & $92(36.8)$ \\
CCB & $64(25.6)$ \\
DIU & $18.6)$ \\
\hline
\end{tabular}

\#, Naira (Nigerian currency); ACEl, angiotensin converting enzyme inhibitor; ARB, angiotensin II receptor blocker; ASA, aspirin; CCB, calcium channel blocker; DIU, diuretic.

alValue may not sum up to $100 \%$ due to combination of antihypertensive medications.

of the participants were on low dose Aspirin in combination with antihypertensive medications. The mean age of all participants was $61.6 \pm 10.2$ years. All participants were comparable in all physical characteristics and cardiovascular parameters $(P>0.05)$, but significant differences were found in BMI and SBP between sexes $(P<0.05)$. Furthermore, no significant difference was found in PA (MET-min/wk) $(P>0.05)$. About $63.6 \%$ of participants reported sufficient PA while $78.4 \%$ was either overweight or obese (Table 2). Table 3 shows comparison of HRQoL of patients with hypertension by PA and body weight status. The results show that 
Table 2. Comparison of anthropometric characteristics, cardiovascular parameters, physical activity and body weight status by sex

\begin{tabular}{|c|c|c|c|c|c|}
\hline Variable & Male $(n=102)$ & Female $(n=148)$ & $t$-cal. & $\chi^{2}$ & $P$-value \\
\hline Age (yr) & $62.4 \pm 9.2$ & $62.3 \pm 9.9$ & -0.47 & & 0.923 \\
\hline Weight (kg) & $68.8 \pm 12.4$ & $70.3 \pm 16.1$ & -0.29 & & 0.091 \\
\hline Height (m) & $1.64 \pm 0.1$ & $1.60 \pm 0.1$ & 0.02 & & 0.946 \\
\hline $\mathrm{BMI}\left(\mathrm{kg} / \mathrm{m}^{2}\right)$ & $25.5 \pm 4.2$ & $29.2 \pm 5.9$ & -1.83 & & $0.025^{*}$ \\
\hline $\mathrm{SBP}(\mathrm{mmHg})$ & $142.4 \pm 19.9$ & $147.1 \pm 24.8$ & 0.74 & & $0.031^{*}$ \\
\hline $\mathrm{DBP}(\mathrm{mmHg})$ & $84.9 \pm 13.7$ & $86.3 \pm 14.6$ & -0.28 & & 0.422 \\
\hline HR (beat/min) & $78.2 \pm 14.1$ & $80.5 \pm 14.6$ & -0.48 & & 0.092 \\
\hline PA (MET-min/wk) & $3,600 \pm 2,500$ & $3,300 \pm 2,800$ & -1.05 & & 0.121 \\
\hline PA & & & & 1.89 & 0.418 \\
\hline Sufficient & $65(26.0)$ & $94(37.6)$ & & & \\
\hline Insufficient & $36(10.4)$ & $54(21.6)$ & & & \\
\hline BWS category & & & & 1.30 & $0.025^{*}$ \\
\hline Normal & $28(11.2)$ & $26(10.4)$ & & & \\
\hline Overweight & $40(16.0)$ & $69(27.6)$ & & & \\
\hline Obese & $34(13.6)$ & $53(21.2)$ & & & \\
\hline
\end{tabular}

Values are presented as mean \pm standard deviation or number (\%).

BMI, body mass index; SBP, systolic blood pressure; DBP, diastolic blood pressure; HR, heart rate; PA, physical activity; MET, metabolic equivalent; BWS, body weight status. ${ }^{*} P<0.05$.

Table 3. Comparison of health-related quality of life of patients with hypertension by physical activity and body weight status

\begin{tabular}{|c|c|c|c|c|c|c|c|c|}
\hline \multirow{2}{*}{ Variable } & \multicolumn{4}{|c|}{ Physical activity } & \multicolumn{4}{|c|}{ BWS group } \\
\hline & Sufficient & Insufficient & $t$-cal. & $P$-value & Overweight & Obese & $t$-cal. & $P$-value \\
\hline Physical functioning & $73.8 \pm 21.2$ & $48.1 \pm 35.0$ & -1.72 & $0.001^{* * *}$ & $64.5 \pm 21.4$ & $60.2 \pm 34.8$ & 0.07 & 0.281 \\
\hline RLdPhp & $54.5 \pm 39.6$ & $46.4 \pm 37.7$ & -0.94 & $0.012^{*}$ & $48.3 \pm 40.4$ & $45.8 \pm 41.6$ & -0.18 & 0.426 \\
\hline RLdEmp & $67.4 \pm 42.3$ & $44.2 \pm 38.1$ & -0.51 & $0.008^{*}$ & $56.7 \pm 46.2$ & $53.6 \pm 47.3$ & 0.09 & 0.174 \\
\hline Vitality & $64.2 \pm 16.7$ & $48.1 \pm 14.2$ & 0.68 & $0.022^{*}$ & $62.0 \pm 15.4$ & $55.3 \pm 24.7$ & -0.06 & 0.148 \\
\hline Emotional well-being & $84.6 \pm 14.7$ & $79.9 \pm 22.7$ & 0.39 & $0.028^{*}$ & $85.3 \pm 18.0$ & $84.6 \pm 16.8$ & 0.14 & 0.528 \\
\hline Social functioning & $76.5 \pm 26.2$ & $51.6 \pm 34.6$ & -1.81 & $0.001^{* * *}$ & $78.5 \pm 27.0$ & $76.3 \pm 30.6$ & 0.28 & 0.462 \\
\hline Bodily pain & $72.8 \pm 24.6$ & $67.8 \pm 36.2$ & 0.58 & 0.129 & $84.6 \pm 23.9$ & $62.4 \pm 25.2$ & -1.82 & $0.016^{*}$ \\
\hline General health & $69.8 \pm 22.5$ & $44.1 \pm 24.7$ & -1.84 & $0.001^{* * *}$ & $66.6 \pm 16.8$ & $63.7 \pm 28.9$ & -0.02 & 0.247 \\
\hline PCS & $68.9 \pm 24.2$ & $47.2 \pm 26.8$ & -1.62 & $0.001^{* * *}$ & $62.7 \pm 26.1$ & $59.9 \pm 26.2$ & 0.37 & 0.203 \\
\hline MCS & $75.3 \pm 16.5$ & $52.1 \pm 21.7$ & -1.48 & $0.001^{* * *}$ & $73.4 \pm 16.9$ & $69.2 \pm 24.8$ & 0.49 & 0.316 \\
\hline
\end{tabular}

Values are presented as mean \pm standard deviation.

BWS, body weight status; RLdPhp, role limitation due to physical health problem; RLdEmp, role limitation due to emotional problem; PCS, physical composite summary; MCS, mental composite summary.

${ }^{*} P<0.05$. ${ }^{* *} P<0.001$.

all domains of HRQoL of participants with sufficient PA were significantly higher (better) than those with insufficient PA except the bodily pain domain. Among participants with overweight/ obese, the HRQoL decreases in all domains with increasing body weight, however, significant difference was found in bodily pain domain $(P<0.05)$. Furthermore, two subscales of the HRQoL including role limitation due to physical health problems (RLdPhp) and emotional problem (RLdEmp) had the worst scores (Table 3).

Table 4 shows comparison of HRQoL of patients with hypertension with respect to sufficient and insufficient PA adjusted for body weight. When adjusted for body weight, the impact of PA was more pronounced on HRQoL. Among participants who reported sufficient PA and belonged to either normal weight or overweight/obese category, the HRQoL scores were higher (better) in all domains including PCS and MCS than those with insufficient. Among normal body weight category, significant differences were found in $\mathrm{HRQ} Q \mathrm{~L}$ between those with sufficient and insufficient PA; physical functioning $(t=-1.72, P=0.001)$, vitality ( $t=0.68, P=0.022)$, emotional well-being $(t=0.39, P=0.028)$, social functioning $(t=-1.81, P=0.001)$, general health $(t=-1.84$, 
Table 4. Comparison of HRQoL of patients with hypertension with respect to sufficient and insufficient PA adjusted for body weight status

\begin{tabular}{|c|c|c|c|c|c|c|c|c|}
\hline \multirow{2}{*}{ HRQoL } & \multicolumn{4}{|c|}{ Normal weight } & \multicolumn{4}{|c|}{ Overweight/obese } \\
\hline & Sufficient & Insufficient & $t$-cal. & $P$-value & Sufficient & Insufficient & $t$-cal. & $P$-value \\
\hline Physical functioning & $79.4 \pm 20.6$ & $48.1 \pm 28.8$ & -2.63 & $0.001^{* * *}$ & $67.7 \pm 27.6$ & $44.3 \pm 31.9$ & -0.98 & $0.012^{*}$ \\
\hline RLdPhp & $54.0 \pm 48.4$ & $40.0 \pm 36.2$ & -1.41 & $0.042^{*}$ & $54.3 \pm 43.3$ & $30.6 \pm 37.9$ & 0.84 & $0.026^{*}$ \\
\hline RLdEmp & $55.6 \pm 44.9$ & $42.8 \pm 46.6$ & 0.73 & 0.181 & $63.9 \pm 45.0$ & $35.2 \pm 45.0$ & -1.62 & $0.018^{*}$ \\
\hline Vitality & $64.0 \pm 15.2$ & $46.5 \pm 22.4$ & 0.96 & $0.037^{*}$ & $63.5 \pm 20.2$ & $52.6 \pm 18.7$ & -1.03 & $0.042^{*}$ \\
\hline Emotional well-being & $80.2 \pm 17.4$ & $63.6 \pm 22.5$ & -1.48 & $0.006^{*}$ & $83.4 \pm 13.1$ & $81.3 \pm 18.3$ & 0.08 & 0.590 \\
\hline Social functioning & $85.0 \pm 22.8$ & $49.8 \pm 45.0$ & -1.69 & $0.005^{*}$ & $79.8 \pm 23.7$ & $70.1 \pm 36.2$ & 0.16 & 0.141 \\
\hline Bodily pain & $74.6 \pm 32.5$ & $66.5 \pm 32.2$ & 0.37 & 0.246 & $75.8 \pm 24.4$ & $65.7 \pm 32.2$ & 0.04 & 0.162 \\
\hline General health & $75.7 \pm 14.6$ & $53.6 \pm 26.5$ & -1.82 & $0.004^{*}$ & $64.6 \pm 20.6$ & $48.5 \pm 19.6$ & -2.31 & $0.008^{*}$ \\
\hline PCS & $68.2 \pm 23.6$ & $43.7 \pm 24.9$ & -2.14 & $0.002^{*}$ & $65.6 \pm 21.3$ & $49.3 \pm 24.2$ & -1.42 & $0.027^{*}$ \\
\hline MCS & $76.3 \pm 15.9$ & $54.2 \pm 28.4$ & 1.85 & $0.008^{*}$ & $72.9 \pm 19.5$ & $59.8 \pm 20.8$ & 0.96 & $0.018^{*}$ \\
\hline
\end{tabular}

Values are presented as mean \pm standard deviation.

HRQoL, health-related quality of life; PA, physical activity; RLdPhp, role limitation due to physical health problem; RLdEmp, role limitation due to emotional problem; PCS, physical composite summary; MCS, mental composite summary.

${ }^{*} P<0.05 .{ }^{* *} P<0.001$

Table 5. Relationships between HROoL domains, age, BMI, and PA (MET-min/wk)

\begin{tabular}{lccl}
\hline HRQoL & Age & BMl & \multicolumn{1}{c}{ PA } \\
\hline Physical functioning & $-0.05(0.125)$ & $0.06(0.136)$ & $0.54(0.001)^{* * *}$ \\
RLdPhp & $-0.08(1.62)$ & $0.02(0.334)$ & $0.29(0.001)^{* * *}$ \\
RLdEmp & $0.14(0.527)$ & $0.08(0.129)$ & $0.39(0.426)$ \\
Vitality & $-0.07(0.402)$ & $0.11(0.627)$ & $0.33(0.001)^{* * *}$ \\
Emotional well-being & $0.12(0.221)$ & $0.21(0.625)$ & $0.06(0.219)$ \\
Social functioning & $-0.05(1.056)$ & $0.16(0.386)$ & $0.21(0.027)^{*}$ \\
Bodily pain & $0.18(0.931)$ & $0.14(0.402)$ & $0.09(0.073)$ \\
General health & $0.09(1.045)$ & $-0.12(0.611)$ & $0.34(0.001)^{* * *}$ \\
PCS & $0.04(1.250)$ & $0.19(0.269)$ & $0.51(0.001)^{* * *}$ \\
MCS & $0.06(1.823)$ & $0.17(0.305)$ & $0.44(0.001)^{* * *}$ \\
\hline
\end{tabular}

Values are presented as $r(P$-value).

HRQDL, health-related quality of life; BMl, body mass index; PA, physical activity; MET, metabolic equivalent; RLdPhp, role limitation due to physical health problem; RLdEmp, role limitation due to emotional problem, PCS, physical composite summary; MCS, mental composite summary.

${ }^{*} P<0.05 .{ }^{* *} P<0.001$

$P=0.001), \operatorname{PCS}(t=-1.62, P=0.001)$, and MCS $(t=-1.48, P=$ 0.001). Furthermore, among participants with overweight and obese categories, significant differences were found in all domains of HRQoL between participants with sufficient PA and insufficient PA except in social functioning and bodily pain $(P>0.05)$.

Table 5 shows the relationships between HRQoL domains, age, BMI and PA (MET-min/wk). The results showed that PA demonstrated significant correlations with HRQoL in all domains including both PCS and MCS $(P<0.05)$. However, there were no significant correlations between PA and each of RLdEmp, emotional well-being and bodily pain domains $(P>0.05)$. Furthermore, the relationships between HRQoL, age and BMI showed no significant correlation $(P>0.05)$. Tables 6 and 7 showed regression models for predicting the influence of age, sex, BMI and PA on HRQoL. Additionally, the results showed that age, sex, $\mathrm{BMI}$, and PA were significantly predictive of physical functioning $\left(R^{2}=0.24, P<0.001\right)$, RLdPhp $\left(R^{2}=0.12, P<0.01\right)$, RLdEmp $\left(R^{2}=0.14, P<0.02\right)$, general health $\left(R^{2}=0.12, P<0.01\right)$, emotional well-being $\left(R^{2}=0.06, P<0.03\right)$, PCS $\left(R^{2}=0.18, P<0.001\right)$, and $\operatorname{MCS}\left(R^{2}=0.15, P<0.01\right)$.

\section{DISCUSSION}

This study investigated the joint predictability of PA and BWS on HRQoL of Nigerian patients with mild to moderate hypertension. Finding from our study showed that a majority of participants in this study was either overweight or obese. This is consistent with findings of previous studies that increasing body weight is associated with high prevalence of hypertension (Wang et al., 2006; Wolk et al., 2003). Similarly, evidence from previous studies showed that presence of increased body adiposity especially abdominal fat is an important risk factor for hypertension and CVD event (Doll et al., 2002; Tesfaye et al., 2007). The plausible explanation for this may be due to persistent peripheral resistance, heavy afterload on the heart and damage to the autonomic nervous system, thus, causing increased sympathetic nerve activity, and disrupting the renin-angiotensin systems (Beevers et al., 2001; Giles et al., 2005). This disruption and several obesity-related issues, psychological, psychosocial and adverse effects of antihypertensive medications are likely risk factors associated with impairment of HRQoL of patients with hypertension (Ogunlana et al., 
Table 6. Physical activity and body weight status predicting physical functioning, role limitation due to physical health and role limitation due emotional problem of health-related quality of life (multiple regressions of significant predictors, in blocks)

\begin{tabular}{|c|c|c|c|c|c|c|c|c|c|}
\hline \multirow{2}{*}{ Variable } & \multicolumn{3}{|c|}{ Model 1} & \multicolumn{3}{|c|}{ Model 2} & \multicolumn{3}{|c|}{ Model 3} \\
\hline & $\beta$ & SEB & $t$ & $\beta$ & SEB & $t$ & $\beta$ & SEB & $t$ \\
\hline \multicolumn{10}{|c|}{ Physical functioning } \\
\hline Age & -0.22 & 0.26 & -0.83 & -0.12 & 0.28 & -0.42 & 0.05 & 0.26 & 0.14 \\
\hline Sex & -6.11 & 4.38 & -1.22 & -5.42 & 4.33 & -1.23 & -7.86 & 4.33 & -1.58 \\
\hline PA & & & & 0.002 & 0.001 & $3.87^{* * *}$ & 0.002 & 0.001 & $3.83^{* * *}$ \\
\hline $\mathrm{BMl}$ & & & & & & & 0.54 & 0.52 & 1.64 \\
\hline $\mathrm{R}^{2}$ & 0.02 & & & 0.16 & & & 0.24 & & \\
\hline $\mathrm{F}$ & 1.28 & & & $7.16^{* *}$ & & & $5.24^{* * *}$ & & \\
\hline \multicolumn{10}{|l|}{ RLdPhp } \\
\hline Age & -0.18 & 0.38 & -0.32 & 0.01 & 0.37 & 0.03 & 0.36 & 0.39 & 0.93 \\
\hline Sex & -10.44 & 6.35 & -1.28 & -8.16 & 5.86 & -1.14 & -12.58 & 6.53 & -1.47 \\
\hline PA & & & & 0.002 & 0.001 & $3.64^{* * *}$ & 0.002 & 0.001 & $3.71^{* * *}$ \\
\hline $\mathrm{BMl}$ & & & & & & & 0.86 & 0.58 & 1.38 \\
\hline $\mathrm{R}^{2}$ & 0.02 & & & 0.01 & & & 0.12 & & \\
\hline $\mathrm{F}$ & 0.72 & & & $4.35^{* *}$ & & & $3.87^{* *}$ & & \\
\hline \multicolumn{10}{|l|}{ RLdEmp } \\
\hline Age & 0.32 & 0.34 & 1.04 & 0.38 & 0.33 & 1.32 & 0.64 & 0.35 & 2.32 \\
\hline Sex & -4.75 & 6.48 & -0.52 & -3.41 & 6.31 & -0.47 & -7.24 & 6.83 & 0.66 \\
\hline PA & & & & 0.002 & 0.001 & $2.24^{* *}$ & 0.002 & 0.001 & $2.26^{* *}$ \\
\hline $\mathrm{BMl}$ & & & & & & & 0.72 & 0.56 & 1.21 \\
\hline $\mathrm{R}^{2}$ & 0.01 & & & 0.04 & & & 0.14 & & \\
\hline $\mathrm{F}$ & 0.56 & & & $2.58^{*}$ & & & $2.96^{*}$ & & \\
\hline
\end{tabular}

SEB, standard error of beta; PA, physical activity; BMI, body mass index; RLdPhp, role limitation due to physical health problem; RLdEmp, role limitation due to emotional problem. ${ }^{*} P<0.05 .{ }^{*} P<0.01$. ${ }^{* *} P<0.001$ (two-tailed).

\section{9; Pan et al., 2011).}

Findings from our study show that the HRQoL of participants with sufficient PA is significantly higher (better) than those with insufficient PA. This is similar to findings of previous study that individuals with hypertension who participate regularly in PA programme are more likely to have better HRQoL than their sedentary counterparts (Jeon et al., 2009; Tsai et al., 2004). Exercise has the capability to improve cardiovascular health by increasing cardiorespiratory fitness, lowers blood pressure and increase self-esteem and subsequently improve HRQoL (Mutrie, 2000; Warburton et al., 2006). Furthermore, PA was found to have significant correlation with all subscales of HRQoL. The reason for the significant relationship may be as a result of brain's contribution to the activation and releasing of endogenous substances including serotonin, beta-endorphin and beta-lipotrophin during regular physical exercise (Meeusen and De Meirleir, 1995; Schwarz and Kindermann, 1989). It is believed that the impact of PA on physiological and psychological functioning bring about a sense of euphoria and pleasure as well as low risk of depression and subsequently lead to improved HRQoL.
On the contrary, there were no significant correlation between PA and each of RLdEmp, emotional well-being and bodily pain domains. This is inconsistent with findings of previous studies which stated that regular PA is capable of relieving emotional well-being and reduce risk of depression (De Moor et al., 2006; Dunn et al., 1999). The possible explanation for nonsignificant relationship may be as a result of other factors affecting overall health of individuals with hypertension. Hypertension is associated with labelling, adverse effect of antihypertensive medications and anxiety and this probably responsible for lower scores in the aforementioned subscales. Similarly, findings from our study show that two subscales of the HRQoL including RLdPhp and RLdEmp had the worst scores. This may be due to common symptoms such as fatigue, frequent headache, dizziness and comorbidities associated with hypertension (Ketelhut et al., 2004; Kjellgren et al., 1998).

Optimal body composition and body weight control is an important lifestyle modification for achieving healthy living (Kohl et al., 2012). Though body weight might not drastically reduce in most individuals participating in PA programme and rehabilitation, appreciable improvement in cardiovascular health and 
Table 7. Physical activity and body weight predicting emotional well-being, general health, physical and mental composite summary of health-related quality of life (multiple regressions of significant predictors, in blocks)

\begin{tabular}{|c|c|c|c|c|c|c|c|c|c|}
\hline \multirow{2}{*}{ Variable } & \multicolumn{3}{|c|}{ Model 1} & \multicolumn{3}{|c|}{ Model 2} & \multicolumn{3}{|c|}{ Model 3} \\
\hline & $\beta$ & SEB & $t$ & $\beta$ & SEB & $t$ & $\beta$ & SEB & $t$ \\
\hline \multicolumn{10}{|c|}{ Emotional well-being } \\
\hline Age & 0.24 & 0.15 & 1.89 & 0.25 & 0.15 & 1.98 & 0.28 & 0.128 & 2.05 \\
\hline Sex & -2.28 & 2.92 & -0.68 & -2.09 & 2.93 & -0.61 & -3.27 & 3.24 & -1.23 \\
\hline PA & & & & 0.00 & 0.00 & 0.88 & 0.00 & 0.00 & 1.32 \\
\hline $\mathrm{BMl}$ & & & & & & & 0.54 & 0.22 & $2.25^{*}$ \\
\hline $\mathrm{R}^{2}$ & 0.02 & & & 0.03 & & & 0.06 & & \\
\hline $\mathrm{F}$ & 1.88 & & & 1.54 & & & $2.55^{*}$ & & \\
\hline \multicolumn{10}{|c|}{ General health } \\
\hline Age & 0.05 & 0.19 & 0.42 & 0.10 & 0.18 & 0.92 & 0.21 & 0.19 & 1.84 \\
\hline Sex & -3.22 & 3.26 & -1.02 & 2.28 & 2.66 & -0.69 & -3.27 & 4.38 & -0.90 \\
\hline PA & & & & 0.001 & 0.00 & $3.28^{* * *}$ & 0.001 & 0.00 & $3.12^{* *}$ \\
\hline $\mathrm{BMl}$ & & & & & & & 0.24 & 0.26 & 0.88 \\
\hline $\mathrm{R}^{2}$ & 0.01 & & & 0.12 & & & 0.14 & & \\
\hline $\mathrm{F}$ & 0.66 & & & $4.32^{* *}$ & & & $3.68^{* *}$ & & \\
\hline \multicolumn{10}{|l|}{ PCS } \\
\hline Age & 0.00 & 0.22 & -0.001 & 0.11 & 0.21 & 0.48 & 0.26 & 0.22 & 1.63 \\
\hline Sex & -4.48 & 4.82 & -1.24 & -4.53 & 4.18 & -1.22 & -6.47 & 4.44 & -1.38 \\
\hline PA & & & & 0.004 & 0.00 & $4.32^{* * *}$ & 0.004 & 0.00 & $4.02^{* *}$ \\
\hline $\mathrm{BMl}$ & & & & & & & 0.42 & 0.40 & 1.06 \\
\hline $\mathrm{R}^{2}$ & 0.01 & & & 0.13 & & & 0.18 & & \\
\hline$F$ & 0.69 & & & $5.27^{* * * *}$ & & & $4.39^{* * *}$ & & \\
\hline \multicolumn{10}{|l|}{ MCS } \\
\hline Age & 0.16 & 0.18 & 0.78 & 0.21 & 0.18 & 1.26 & 0.42 & 0.19 & 1.94 \\
\hline Sex & -3.42 & 4.38 & -0.92 & -2.74 & 4.17 & -0.84 & -5.46 & 4.36 & -1.56 \\
\hline PA & & & & 0.001 & 0.00 & $2.68^{* *}$ & 0.001 & 0.00 & $3.16^{* *}$ \\
\hline $\mathrm{BMl}$ & & & & & & & 0.88 & 0.45 & 1.84 \\
\hline $\mathrm{R}^{2}$ & 0.02 & & & 0.06 & & & 0.15 & & \\
\hline $\mathrm{F}$ & 0.82 & & & $3.24^{*}$ & & & $3.65^{* *}$ & & \\
\hline
\end{tabular}

SEB, standard error of beta; PA, physical activity; BMI, body mass index; PCS, Physical composite summary; MCS, Mental composite summary.

${ }^{*} P<0.05 .{ }^{*} P<0.01$. ${ }^{* * *} P<0.001$ (two-tailed).

HRQoL appear to be better than individuals who are less active (Maruf et al., 2013; Pan et al., 2011). In our study, when adjusted for body weight, participants with sufficient PA irrespective of body weight status demonstrated better HRQoL than those with insufficient PA despite normal weight. This finding substantiates the fact that sufficient PA is beneficial for healthy living and predicts better HRQoL among individuals with hypertension. The PA level of participants in our study appears to be moderate. This is contrary to findings of previous studies that patients with hypertension usually have low PA level (Awotidebe et al., 2016; Eugene and Bourne, 2013). The moderate PA level observed in our study might be due to regular advice received from physicians and other healthcare professionals emphasizing participation in regular and sufficient PA programme in addition to daily antihyperten- sive medications. Similarly, in our study, we found that the impact of PA was more pronounced on HRQoL regardless of body weight status. This corroborated findings of previous studies that PA is strongly associated with overall well-being, reduce risk of CVD event and adequate HRQoL (Hallal et al, 2012; Warburton et al., 2006). There is no doubt that persistent physical inactivity and increasing body weight gain in hypertension are important malefactors for unprecedented risk of CVD event and poor HRQoL. Undoubtedly, Warburton et al. (2006) concluded that there is incontrovertible evidence that regular PA contributes to the primary and secondary prevention of several chronic diseases and is associated with a reduced risk of premature death such that most physically active people are at the lowest risk.

The outcome of this study should be interpreted with caution 
because of some limitations inherent therein. The PA and HRQoL were assessed using the self-reported questionnaire which might be overestimated or underestimated. More importantly, the HRQoL is a variable that can only be subjectively assessed and many factors including individual's mood, circumstances surrounding treatment such as the provision of adequate medical services, and personal challenges or achievements may influence the assessment of HRQoL. Upto this present moment, there appears to be scarcity of disease specific-HRQoL instrument for patients with hypertension, hence, only generic ones are in use among this population. However, regardless of SF-36 being a generic instrument for assessing HRQoL, several studies have used it among patients with hypertension and found it appropriate in the assessment of HRQoL. For future research involving PA assessment, we suggest that PA assessment should include objective measures such as pedometer-determined PA in order to valid findings of this study. In conclusion, patients with mild to moderate hypertension who reported sufficient PA demonstrated higher and significant HRQoL than those with insufficient PA irrespective of body weight status. Furthermore, sufficient PA is a better predictor of HRQoL among patients with hypertension thus, supporting findings from previous studies. It is important to consider regular assessment of HRQoL of patients with hypertension in order to identify individuals at risk of poor health status and thus provide immediate care in order to achieve both physical and mental well-being. More importantly, regular PA is recommended for patients with hypertension to improve cardiovascular health and satisfying HRQoL.

\section{CONFLICT OF INTEREST}

No potential conflict of interest relevant to this article was reported.

\section{ACKNOWLEDGEMENTS}

The authors wish to thank the Consortium for Advanced Research Training in Africa (CARTA) for providing technical support. CARTA is jointly led by the African Population and Health Research Center and the University of the Witwatersrand and funded by the Wellcome Trust (UK) (Grant No. 087547/Z/08/Z), the Department for International Development (DfID) under the Development Partnerships in Higher Education (DelPHE), the Carnegie Corporation of New York (Grant No. B 8606), the Ford Foundation (Grant No. 1100-0399), Swedish International De- velopment Corporation Agency - SIDA (grant: 54100029), Google.Org (Grant No. 191994), and MacArthur Foundation Grant No. 10-95915-000-INP.

\section{REFERENCES}

Abramson JH, Gahlinger PM. Computer programs for epidemiologists: PEPI V.4.0. Salt Lake City (UT): Sagebrush Press; 2001.

Adedoyin RA, Mbada CE, Balogun MO, Martins T, Adebayo RA, Akintomide A, Akinwusi PO. Prevalence and pattern of hypertension in a semiurban community in Nigeria. Eur J Cardiovasc Prev Rehabil 2008;15:683-687.

Alberts M, Urdal P, Steyn K, Stensvold I, Tverdal A, Nel JH, Steyn NP. Prevalence of cardiovascular diseases and associated risk factors in a rural black population of South Africa. Eur J Cardiovasc Prev Rehabil 2005;12:347-354.

Awotidebe TO, Adedoyin RA, Rasaq WA, Adeyeye VO, Mbada CE, Akinola OT, Otwombe KN. Knowledge, attitude and practice of exercise for blood pressure control: a cross-sectional survey. J Exerc Sci Physiother 2014;10:1-10.

Awotidebe TO, Adeyeye VO, Ativie RN, Adedoyin RA, Borode AO, Balogun MO, Akindele MA. Functional capacity and psychosocial correlates of exercise in Nigerian patients with hypertension. Int J Clin Med 2016;7:464-473.

Beevers G, Lip GY, O'Brien E. ABC of hypertension: The pathophysiology of hypertension. BMJ 2001;322:912-916.

BeLue R, Okoror TA, Iwelunmor J, Taylor KD, Degboe AN, Agyemang C, Ogedegbe G. An overview of cardiovascular risk factor burden in sub-Saharan African countries: a socio-cultural perspective. Global Health 2009;5:10.

Bull FC, Bauman AE. Physical inactivity: the "Cinderella" risk factor for noncommunicable disease prevention. J Health Commun 2011;16 Suppl 2:13-26.

Bygbjerg IC. Double burden of noncommunicable and infectious diseases in developing countries. Science 2012;337:1499-1501.

Chobanian AV, Bakris GL, Black HL, Cushman WC, Green LA, Izzo JL. The seventh report of the joint national committee on prevention, detection, evaluation, and treatment of high blood pressure. Hypertension 2003;42:1206-1252.

De Moor MH, Beem AL, Stubbe JH, Boomsma DI, De Geus EJ. Regular exercise, anxiety, depression and personality: a population-based study. Prev Med 2006;42:273-279.

Doll S, Paccaud F, Bovet P, Burnier M, Wietlisbach V. Body mass index, abdominal adiposity and blood pressure: consistency of their association across developing and developed countries. Int J Obes Relat Me- 
tab Disord 2002;26:48-57.

Dunn AL, Marcus BH, Kampert JB, Garcia ME, Kohl HW 3rd, Blair SN. Comparison of lifestyle and structured interventions to increase physical activity and cardiorespiratory fitness: a randomized trial. JAMA 1999;281:327-334.

Ekwunife OI, Aguwa CN, Adibe MO, Barikpaoar E, Onwuka CJ. Health state utilities of a population of Nigerian hypertensive patients. BMC Res Notes 2011;4:528.

Eugene V, Bourne PA. Hypertensive patients: knowledge, Self-care management practices and challenges. J Behav Health 2013;2:259-268.

Familoni OB, Alebiosu CO, Odusan O, Raimi A. Factors influencing target organ damage among hypertensive patients in Nigeria. Trop Cardiol 2004;29:21-24.

Giles TD, Berk BC, Black HR, Cohn JN, Kostis JB, Izzo JL Jr, Weber MA. Expanding the definition and classification of hypertension. J Clin Hypertens (Greenwich) 2005;7:505-512.

Hajjar I, Kotchen JM, Kotchen TA. Hypertension: trends in prevalence, incidence, and control. Annu Rev Public Health 2006;27:465-490.

Hallal PC, Andersen LB, Bull FC, Guthold R, Haskell W, Ekelund U; Lancet Physical Activity Series Working Group. Global physical activity levels: surveillance progress, pitfalls, and prospects. Lancet 2012;380: 247-257.

Jeon EY, Kim SY, Yoo HS. Effects of music therapy and rhythmic exercise on quality of life, blood pressure and upper extremity muscle strength in institution-dwelling elderly women. J Korean Acad Nurs 2009;39: 829-839.

Kearney PM, Whelton M, Reynolds K, Muntner P, Whelton PK. Global burden of hypertension: analysis of worldwide data. Lancet 2005;365: 217-223.

Ketelhut RG, Franz IW, Scholze J. Regular exercise as an effective approach in antihypertensive therapy. Med Sci Sports Exerc 2004;36:4-8.

Kjellgren KI, Ahlner J, Dahlöf B, Gill H, Hedner T, Säljö R. Perceived symptoms amongst hypertensive patients in routine clinical practicea population-based study. J Intern Med 1998;244:325-332.

Kohl HW 3rd, Craig CL, Lambert EV, Inoue S, Alkandari JR, Leetongin G, Kahlmeier S; Lancet Physical Activity Series Working Group. The pandemic of physical inactivity: global action for public health. Lancet 2012;380:294-305.

Maruf FA, Akinpelu AO, Salako BL. Self-reported quality of life before and after aerobic exercise training in individuals with hypertension: a randomised-controlled trial. Appl Psychol Health Well Being 2013;5: 209-224.

Mbada CE, Adeogun GA, Ogunlana MO, Adedoyin RA, Akinsulore A, Awotidebe TO, Idowu OA, Olaoye OA. Translation, cross-cultural adaptation and psychometric evaluation of yoruba version of the short-form 36 health survey. Health Qual Life Outcomes 2015;13:141.

Meeusen R, De Meirleir K. Exercise and brain neurotransmission. Sports Med 1995;20:160-188.

Mutrie, N. The relationship between physical activity and clinically defined depression. In Biddle SJH, Fox KR, Boutcher H, editors. Physical activity and psychological well-being. London: Routledge; 2000. p. 4662.

Ogunlana MO, Adedokun B, Dairo MD, Odunaiya NA. Profile and predictor of health-related quality of life among hypertensive patients in south-western Nigeria. BMC Cardiovasc Disord 2009;9:25.

Oyeyemi AL, Oyeyemi AY, Adegoke BO, Oyetoke FO, Aliyu HN, Aliyu SU, Rufai AA. Cross cultural adaptation of the International Physical Activity Questionnaire: Reliability and validity of the Hausa version in Nigeria. BMC Med Res Methodol 2011;11:156.

Pan HJ, Cole BM, Geliebter A. The benefits of body weight loss on health-related quality of life. J Chin Med Assoc 2011;74:169-175.

Pescatello LS, Franklin BA, Fagard R, Farquhar WB, Kelley GA, Ray CA; American College of Sports Medicine. American College of Sports Medicine position stand. Exercise and hypertension. Med Sci Sports Exerc 2004;36:533-553.

Salako BL, Adebiyi AA, Oladapo OO, Ogah OS, Aje A. Left ventricular wall dimensions of people with hypertension on treatment. Trop Cardiol 2004;30:39-41.

Schwarz L, Kindermann W. Changes in beta-endorphin levels in response to aerobic and anaerobic exercise. Sports Med 1992;13:25-36.

Sobngwi E, Mbanya JC, Unwin NC, Kengne AP, Fezeu L, Minkoulou EM, Aspray TJ, Alberti KG. Physical activity and its relationship with obesity, hypertension and diabetes in urban and rural Cameroon. Int J Obes Relat Metab Disord 2002;26:1009-1016.

Tesfaye F, Nawi NG, Van Minh H, Byass P, Berhane Y, Bonita R, Wall S. Association between body mass index and blood pressure across three populations in Africa and Asia. J Hum Hypertens 2007;21:28-37.

Tsai JC, Yang HY, Wang WH, Hsieh MH, Chen PT, Kao CC, Kao PF, Wang $\mathrm{CH}$, Chan $\mathrm{P}$. The beneficial effect of regular endurance exercise training on blood pressure and quality of life in patients with hypertension. Clin Exp Hypertens 2004;26:255-265.

van de Vijver S, Akinyi H, Oti S, Olajide A, Agyemang C, Aboderin I, Kyobutungi C. Status report on hypertension in Africa: consultative review for the 6th Session of the African Union Conference of Ministers of Health on NCD's. Pan Afr Med J 2013;16:38.

Wang W, Lee ET, Fabsitz RR, Devereux R, Best L, Welty TK, Howard BV. A longitudinal study of hypertension risk factors and their relation to cardiovascular disease: the Strong Heart Study. Hypertension 2006; 47:403-409.

Warburton DE, Nicol CW, Bredin SS. Health benefits of physical activity: 
the evidence. CMAJ 2006;174:801-809.

Ware JE Jr, Gandek B. Overview of the SF-36 Health Survey and the International Quality of Life Assessment (IQOLA) Project. J Clin Epidemiol 1998;51:903-912.

Wolk R, Shamsuzzaman AS, Somers VK. Obesity, sleep apnea, and hypertension. Hypertension 2003;42:1067-1074.

World Health Organization. Cardiovascular diseases in the African region: current situation and perspectives [Internet]. Geneva: World Health Organization; 2005a Aug 25 [cited 2013 June 5]. Available from: http://apps.who.int/iris/bitstream/10665/92865/1/AFR\%20RC55\%20 R4.pdf.

World Health Organization. Chronic diseases. Report of WHO expert consultation [Internet]. Geneva: World Health Organization; 2009 [cited 2015 Aug 12]. Available from: http://www.who.int/topics/chronic_ diseases/en/

World Health Organization. Diet, nutrition and the prevention of chronic diseases. Report of the joint WHO/FAO expert consultation. WHO Technical Report Series, No. 916 (TRS 916) [Internet]. Geneva: World Health Organization; 2003 [cited 2012 Mar 18]. Available from: http:// apps.who.int/iris/bitstream/10665/42665/1/WHO_TRS_916.pdf.

World Health Organization. Global recommendations on physical activity for health [Internet]. Geneva: World Health Organization; 2010 [cited 2015 Nov 15]. Available from: http://www.whqlibdoc.who.int/ publications/2010/9789241599979_eng.pdf.

World Health Organization. Health situation analysis in the African region. Atlas of health statistics, 2011. Geneva: World Health Organization - Regional Office for Africa; 2011.

World Health Organization. Physical status: the use and interpretation of anthropometry. Report of a WHO Expert Committee. WHO Technical Report Series 854. Geneva: World Health Organization; 1995.

World Health Organization. Preventing chronic diseases: a vital investment. Geneva: World Health Organization; 2005b. 